average about ten inches of rainfall a year, which, if all yielded up to wells, would give a daily average supply of 400,000 gallons per square mile, and he further shows that the larger area of these permeable formations lies east of the great water-shed, dividing England diagonally, and separating the Severn and Trent basins on the one side, from those of the Thames, east coast streams, Witham and Ouse on the other, the only important previous formation west of this boundary being the permian and new red sandstones. The latter occupies an area of 3 , 190 square miles.

This different disposition of the permeable and impermeable strata in England, at once explains how it is that the dry-weather flow of rivers like the Thames, draining a basin largely consisting of permeable strata, differs so remarkably in volume from rivers like the Severn, mainly occupied by impermeable silurian rocks and triassic marls, and the necessity is at once apparent of there being a central authority, taking cognisance of all matters bearing on water questions, and assisting parliament in giving or withholding to any corporation or district the water rights of any area to which they may lay claim. Thus, in the case of Liverpool, it is proposed to take from the sources of the Severn, a quantity of not less than 52,000,000 gallons a day, while Mr. Hawksley, in evidence before the Royal Rivers Commission, gives the driest weather flow, so low down the Severn as Tewkesbury, as only $90,000,000$ gallons per day. With a margin so small, it is obvious that the maintaining of a sufficient volume of water for navigation, fisheries, and other purposes, is of national importance, and should be the subject of imperial care.

The basis of all calculations of the body of water available for gravitation purposes must of necessity be an accurate record over numerous localities of the amount of rainfall, and it is a matter of regret that the work carried out by Mr. G. T. Symons is not incorporated with the Meteorological Department of the Government. In 1865 the British Association appointed a Committee to assist Mr. Symons in developing the system of registration; the total number of stations now at work exceed 2,000 , and the correspondence with these observers, the verification of their instruments and codification of their observations necessarily incur a large amount of expenditure. The British Association, after many years' support of the work, feeling it their duty rather to initiate than permanently subsidise investigations, have at length discontinued their grant, and the only sources with which this work of national importance to the country can be carried out by Mr. Symons are voluntary subscriptions and the profits on the annual sale of the volume of "British Rainfall." We trust that one result of the Congress may be to place this work on a more permanent and satisfactory basis, and also that the Ordnance or Geological Survey be charged with the gauging of the chief streams of the country, so that data may be furnished for really estimating what amount of rainfall at once runs off in impermeable districts, and how much is absorbed in permeable districts, without which all calculations as to probable yield are to a great extent hypothetical.

It is the fashion in some quarters to abuse the Local Government Board, but when it is realised that they have no authority given them by legislation to survey the country, seek out abuses, suggest and compel improvements, - until they are called to inspect often by the authorities who have allowed abuses to devastate a particular district,-we think that those who read their annual report of work will give them the greatest credit for the industry and ability with which, often at much personal discomfort, they track not only the fever-germs to their source, but confront the ignoranc and obstinacy of the small local authorities. We hoepe that the action of the Society of Arts, in bringing these matters prominently before the country may lead to the scope of the Local Government Board being so enlarged, theiz staff increased, and their sources of information widened, that they may become a Department of Health, ever ready not merely to find out the cause of disease, but to prevent the possibility of its occurrence. Towards this end, in rousing public opinion to the exigencies of the question, these congresses cannot be, perhaps, too highly valued. Already out of the congress held this year, a National Water Supply Exhibition has been inaugurated at the Royal Aquarium, which cannot but tend to popularise the subject, and if it should be possible to find the Exhibition a permanent home, at the South Kensington Museum, it would add an important factor to the already high educational value of that institution. Should a wider knowledge of these subjects become general, and the government legislate in the direction suggested by the Society, it will be felt that its President, the Prince of Wales, in first bringing the subject prominently before the Society, and in lately placing it before the Premier, will have been instrumental in bringing about the once almost Utopian hope of Charles Dickens, in his preface to the Pickwick Papers, that the time will come when " a few petty boards and bodies-less than drops in the great. ocean of humanity which roars around them--are not for ever to loose fever and consumption on God's creatures, at their will, or always to keep their jobbing little fiddles going for a Dance of Death."

\section{THE AUDIOMETER}

$A$ LREADY have experiments of the greatest practical $A$ value been made with the wonderful invention of Prof. Hughes described in our last number. Dr. B. W. Richardson has been applying it in two ways: as an Audiometer for the measurement of hearing, and a. Sphygmophone for measuring the pulse. Both applications were described at the last meeting of the Royal Society.

The audiometer, as it had been used, was shown to the Society. It consists of two Leclanché's cells for the battery, a new and simple microphonic key connected with the cells and with two fixed primary coils, and a secondary or induction coil, the terminals of which are attached to a telephone. The induction coil moves on a bar between the two fixed coils, and the bar is graduated into 200 parts, by which the readings of sound are taken. The graduated scale is divided into 20 centims., and each of these parts is subdivided into 10 , so that the hearing may be tested from the maximum of 200 units to $0^{\circ}$-zero. The fixed coil on the right hand contains 6 metres of wire; the fixed coil on the left hand contains roo metres. By this means a long scale from the left hand coil is produced. The secondary coil contains 100 metres of wire.

In using the instrument, the induction coil is moved. along the scale from or towards the larger primary, as may be required, and the degrees or units of sound are read from the figures on the scale, the sound being made by the movement of the microphonic key between the battery and the primary coils.

The instrument may be considered to afford the most satisfactory means for testing the hearing power of all persons who can define a sound. The range of sound is sufficient at the maximum-200 -for every one who is not absolutely deaf; $0^{\circ}$, or zero, is a point of positive silence from the instrument, or rather from the sound. which it produces through the telephone.

One of the first facts learned with the audiometer is the suddenness with which the sound is lost to those who are listening. The sound is abruptly lost within a range of $2^{\circ}$; that is, within one-hundredth part of the entire scale. This is the case with those who are very deaf as well as with those who hear readily. 
In testing the capacity of hearing, it is noticeable that the power to detect the diminishing sound is maintained best by continuing the reduction in trace or line while the attention is fixed. A sudden break may cause the sound to be lost to the listener long before his real incapacity to hear is reached. If, for instance, the sound be very faintly heard at $15^{\circ}$, and the induction coil be suddenly moved to $5^{\circ}$, the sound at $5^{\circ}$ may be quite inaudible; but if the coil be slowly moved, unit by unit, from $15^{\circ}$ to $5^{\circ}$, the sound at $5^{\circ}$ nray be distinctly heard.

The effect of filling the chest and holding the breath makes a difference in listeners. The capacity for hearing is for a few seconds increased by holding the breath. Holding the breath with the chest not full fails to produce the same result.

As a rule, the hearing of persons who are right-handed is most refined in the right ear, and as most persons are right-handed, it is found that the right ear is the best ear. This rule is, however, attended with many exceptions, since, for various reasons, some persons who use the right hand exclusively, practise for some particular purpose the use of the left ear, upon which that ear becomes more acute. Another point of interest attaching to this observation is, that the practice of using one ear for special refinement of the sense seems for the time slightly to impair the other ear, although there is no physical evidence of such impairment.

Connected with the last-named fact is another, namely, that by this instrument the deaf are found to fail in capacity of hearing not only by reason of physical defect, but also by failure of memory of sounds. Thus in a youth who had suffered serious defect of hearing for seven years, owing to partial destruction of the tympanum, and who in the right ear could only detect sound at $107^{\circ}$, there was an inability to catch all the sound lying between $130^{\circ}$ and $107^{\circ}$, until he could remember what he had to listen for. By practising him then to detect the lowest sound that he was physically capable of receiving, Dr. Richardson got him to detect this one sound more readily than those which came higher up. By further practice all the intervening sounds became audible with equal facility.

By use of the audiometer the influence of atmospheric pressure on hearing is detectable. In Dr. Richardson's own case, when the barometer is at $30^{\circ}$ he can hear on both sides close down to zero; but below $30^{\circ}$ he fails by $2^{\circ}$ on the left side to reach zero. In another person a similar failure extends to a loss of $4^{\circ}$.

Dr. Richardson has tried to determine in some of the lower animals whether there is the same sense of hearing as in man. In two dogs, one a terrier, the other a field spaniel, the range of hearing power seemed to be distinctly lower than it is in the human subject who has perfect hearing. In both these animals, which were healthy, and in the prime of life, the first indication of the detection of sound commenced at $10^{\circ}$ on the scale.

Dr. Richardson's practical conclusions are--

I. The audiometer will, he thinks, be an essential in all physical examinations of men who are undergoing examination as to their fitness for special services requiring perfect hearing, such as soldiers, sentries, railway officials, and the like. 2. The instrument will be of great use to the physician in determining the value of hearing in those who are deaf, and in determining the relative values of the two organs of hearing. 3. In other forms of diagnosis he has found the instrument useful, as in anæmia and vertigo. 4. The instrument may be used to differentiate between deafness through the external ear and deafness from closure of the Eustachian tube-throat deafness. 5. The instrument promises to be very useful in detecting the effects in the body of those agents which quicken or excite the circulation, such as alcohol and other similar chemical substances. 6 . The instrument promises to be of great service in determining the value of artificial tympanums in instances of reafness due to imperfection or destruction of the natural tympanum. Dr. Richardson finds in fine gold the substance for making the most useful and effective artificial drum.

The sphygmophone, for obtaining a secondary or telephonic sound from the movements of the pulse at the wrist, is devised by adding a microphone to a Pond's sphygmograph. Dr. Richardson mounts on a slip of talc, glass, or wood a thin plate of platinum or gas carbon. He places the slip in the sphygmograph as if about to take a tracing of the pulse. One terminal from a Leclanche's cell is connected to the platinum or carbon, and the second terminal from the cell to a terminal of the telephone, the other terminal of the telephone with the metal rod of the sphygmograph which supports the slip. The instrument is placed on the pulse, in the ordinary way, and is adjusted, with the writing needle thrown back, until a good pulsating movement of the needle is secured. The needle, in passing over the metallic plate, causes a distinct series of sounds from the telephone, which correspond with the movements of the pulse. The sounds are singular, as resembling the two words, "bother it." The sounds can be made very loud by increasing the battery power.

In this connection we may state that in the last number of La Nature a micro-telephonic explorer is described, also evidently of great use in pathology. This is a simple instrument, devised by MM. Charden and Prayer, consisting of a telephonic apparatus with microphonic intermediary to intensify any sounds sought for, and which, among other purposes, will be of great service in detecting any foreign body in a vital organ. The apparatus is quite portable and worked with comparative ease, though doubtless actual practice will suggest improvements both in this and in the applications devised by Dr. Richardson.

\section{A MACHINE FOR DRAWING COMPOUND HARMONIC CURVES ${ }^{1}$}

HARMONIC curves possess great importance, since they represent to the eye the circumstances of motion of bodies in a state of vibration, and hence apply not merely to the pendulum and to musical instruments when giving their tones, but also to the particles of air during the transmission of sound.

The study of these curves offers us two problems of almost equal importance and interest, viz : First, Given the curve; required, to find its component simple elements. Second, Given the component simple curves; required, to construct the resulting compound curve. From the standpoint of acoustics these problems may be stated thus : First, Given a complex sound, required to find the simple musical tones of which it is composed. Second, Given the intensity, pitch, and phase of each of a number of pure musical tones; required, to find the effect of their simultaneous action on the air.

The laborious investigations of Donders, Helmholtz, and others into the constitution of the simplest elements of speech-the vowel sounds-show that the actual analysis of the simplest articulate sound is no easy matter. When the curve corresponding to the sound is once obtained, Fourier's theorem enables us to subject it to mathematical analysis, and thus determine by a somewhat laborious process, its simple harmonic elements. Three methods give us such curves. König ${ }^{2}$ employed two tuning-forks, to actually draw the curre belonging to their combination; this method is limited to combination of two simple tones. Messrs. Jenkin and Ewing ${ }^{3}$ magnified the impression made on the tin-foil of the phonograph, obtaining thus the curve belonging to the sound impressed on the vibrating disk.

$\times$ Abstract of Paper in the American Foumal of Otology for April, by Prof. E. W. Blake, Brown University

Poggendorff's Annalen, Bd. clvii. S. ${ }^{177}, 1876$

3 NATURF, May 9, 1878 ; July 25, 2878 . 